\title{
ESTRUTURA E TEMPORALIDADE NA PSICOLOGIA E NA PSICANÁLISE
}

Isabel Fortes

Psicanalista, doutora em Teoria Psicanalítica pela UFRJ, membro do Espaço Brasileiro de Estudos Psicanalíticos.

RESUMO: Pretende-se fazer uma diferenciação entre a forma como a estrutura é vista pela psicologia e a maneira como é concebida pela psicanálise, com o intuito de analisar a especificidade da noção de estrutura na teoria psicanalítica e a sua importância no que diz respeito à questão da temporalidade. Para isso, a estrutura psicológica é vista, primeiramente, a partir do gestaltismo psicológico, um estruturalismo sem gênese, e, depois, na teoria piagetiana, que introduz a gênese na estrutura. Na estrutura psicanalítica, a temporalidade é da ordem da atual ização, como se pode atestar no conceito de a posteriori (o Nachträglichkeit).

Palavras-chave: Estrutura, temporalidade, gestaltismo, teoria piagetiana, estrutura psicanalítica.

ABSTRACT: Structure and temporality in psychology and psychoanalysis. The article intends to distinguish the way structure is regarded by psychology from the way it is conceived in psychoanalysis, with the aim of analyzing the specificity of the idea of structure in psychoanalytical theory and its importance in relation to temporality. To this effect, psychological structure is seen firstly from the point of view of psychological Gestaltism, a structuralism without genesis, and secondly, in Piagetian theory, which introduces genesis into structure. In psychoanalytical structure temporality is of the order of actualization, as it can be seen in the concept of a posteriori (Nachträglichkét).

Keywords: Structure, Temporality, Gestaltism, Piagetian theory, Psychoanalytical structure.

Dretende-se fazer uma diferenciação entre a forma como a estrutura é vista pela psicologia e a maneira como é concebida pela psicanálise, com o intuito de analisar a especificidade da noção de estrutura na teoria psicanalítica e a sua importância no que diz respeito à questão da temporalidade. 


\section{O GESTALTISMO PSICOLÓGICO}

A noção de estrutura apareceu inicial mente na matemática, da teoria dos grupos de Gallois até as chamadas estruturas matriciais de Bourbaki. A partir do começo do século XX, ganhou espaço em vários outros campos do saber. Dentre esses campos, um dos que mais trabalhou com a noção de estrutura foi a psicologia, por meio da psicologia da forma ou gestaltismo psicológico, nascido em 1912, a partir dos estudos inaugurais de Wertheimer, Koffka e Köhler, integrantes da chamada Escola de Berlim.

Desse modo, a psicologia da forma - que se fundamentou sobre as formulações das teorias da percepção - lançou as bases para a teoria psicológica da estrutura, na qual é fundamental a noção de 'totalidade psíquica'.

A compreensão estrutural, aqui, analisa as realidades como totalidades, não se atendo aos elementos componentes, pois o todo é visto como uma unidade. Esta última só pode existir como um todo, a partir da compreensão básica de que o todo não é igual à soma das partes. Segundo o gestaltismo, é este sentido de unidade estrutural que caracteriza a forma, ao se afirmar uma anterioridade do todo em relação às suas partes. Existe na totalidade psíquica um princípio organizador que faz com que haja uma unidade na qual o todo é diferente da mera soma dos seus elementos componentes:

"A coexistência das partes no todo garante uma organização suprassomativa, cujo princípio unificador não se acrescenta ao conjunto unificado como um último termo, nem tampouco se confunde com a mera associação dos elementos componentes. A forma é o resultado do compromisso estrutural de cada parte com o restante do todo." (PASSOS, 1992, p.113)

Portanto, a totalidade psíquica é regida pelas leis de organização do fenômeno perceptivo, e estas leis se condensam no que o gestaltismo denominou de teoria da Boa Forma - que postula haver uma tendência a organizar as formas perceptivas, levando as excitações fisiológicas a estabilizar a melhor forma possível. Esta tendência à melhor estabilização, postulada pela psicologia da forma, indica que "os fatores de forma, enquanto fatores de estabilidade, organizarão um campo" (KOFFKA, 1975, p.162), e o farão a partir da idéia de que

“a organização psicológica será tão 'boa' quanto as condições reinantes permitirem. Nesta definição, o termo 'boa' é indefinido. Abrange propriedades tais como a regularidade, a simetria, a simplicidade e outras que iremos encontrar no decurso de nosso trabalho." (KOFFKA, 1975, p.121) 
As Gestalten, portanto, são todos dinâmicos que, por suas propriedades funcionais, delimitam modos de organização.

U ma compreensão que se associa de modo direto à lei da Boa Forma é a noção de equilíbrio. A idéia geral é de que o universo é um sistema que tende a se estabilizar com um mínimo de energia. Tomando como paradigma o modelo da física, as forças de um sistema tendem ao equilíbrio e, conseqüentemente, ao consumo mínimo de energia. Por isso, a cognição é pensada como um mecanismo de manutenção do equilíbrio.

N esse sentido, a noção de equilíbrio é central no gestaltismo, estando presente nas várias ciências, o que indica a sua pretensão ao universal, já que "a realidade em geral é pensada como uma Gestalt que se organiza no sentido da estabilização da melhor forma" (PASSOS, 1992, p.125).

A idéia de que qualquer sistema se organiza segundo as leis da Gestalt faz com que 0 que acontece na física seja também verificado no campo da psicologia. Desse modo, o gestaltismo estabelece uma unidade estrutural, que se funda na idéia de um isomorfismo entre o mundo físico e o mundo psíquico, tese que afirma uma harmonia entre razão e universo, refutando a idéia de um conhecimento que viria organizar um mundo caótico.

A noção mesma de forma institui a posição estrutural do gestaltismo, o qual concebe que os fatos psíquicos são formas que se limitam ao campo espacial e temporal de percepção ou de representação. Por isso, a teoria da Gestalt não aceita a oposição entre caos material e atividade organizadora, pois o conhecimento já reflete a organização do objeto (PASSOS, 1992).

Se o que caracteriza a estrutura é haver um modo de organização que constitua um conjunto de elementos relacionados entre si segundo certas regras, ou funcionalmente correlacionados, o traço relevante da estrutura psicológica é a idéia de que o conjunto é uma totalidade e não uma "mera soma": "No processo de organização, o que acontece a uma parte do todo é determinado por leis intrínsecas inerentes a esse todo" (WERTHEIMER apud PASSOS, 1992, p.121).

Assim, a estrutura aponta para um princípio organizacional que atua sobre as partes que compõem qualquer sistema. Compreende-se que é o todo que determina as partes, isto é, determina os elementos eas relações que devem ser mantidas entre eles. Veremos adiante como esta compreensão marca uma nítida distinção da forma como se concebe a estrutura na psicanálise.

Sobre esta noção da determinação do todo sobre as partes, Kurt Lewin, que foi bastante influente no gestal tismo psicológico ao desenvolver o chamado "estruturalismo topológico", usou essa compreensão acerca da totalidade para desenvolver suas pesquisas sobre a dinâmica dos grupos, estendendo a teoria da Gestalt para a psicologia social. No livro Problemas dedinâmica degrupo (1970) , 0 autor apresenta a noção de "totalidade dinâmica" , mostrando como, em um conjunto, 
os elementos são interdependentes. Um grupo, portanto, é um conjunto que possui leis próprias, que ultrapassam o funcionamento particular de cada indivíduo.

No entanto, se nosso interesse neste artigo é ver a relação existente entre a estrutura e a temporalidade, a crítica que se faz ao gestaltismo é que seu princípio estruturante universal acaba por recusar a dimensão temporal, o que o levou a ser acusado de um estruturalismo sem gênese, sem história.

Excluir o fator 'tempo' foi o preço pago pela teoria da Gestalt por seguir o modelo da física para entender o que era verificado pela psicologia: “Nos conjuntos estáticos em equilíbrio não ocorre mudança por períodos longos, havendo uma independência de sua organização em relação ao tempo" (PASSOS, 1992, p.126).

Portanto, as propriedades descritas aqui antes como pertencentes à lei da Boa Forma - a regularidade, a simetria e a simplicidade - são processos que levam à tendência ao equilíbrio, mas que têm como conseqüência neutralizar o fator tempo:

"Tomando, como modelo físico paradigmático, esses processos nos quais a distribuição das forças tende ao equilíbrio e, conseqüentemente, ao consumo mínimo de energia do sistema, essa teoria psicológica constrói seu ideal de inteligibilidade que tem como contrapartida a neutralização da variável tempo." (PASSOS, 1992, p.126)

\section{A PSICOGÊNESE DA ESTRUTURA}

A inovação de Piaget para o estruturalismo foi pensar a gênese da estrutura. Esta última perde 0 caráter estático de permanência para tornar-se uma estrutura estruturante e estruturada que vai se modificando por meio de um princípio de equilibração.

Assim, enquanto o gestaltismo pensava uma estrutura pura, sem gênese, Piaget teve o mérito de incluir a dimensão do tempo na estrutura, criticando a noção de totalidade formulada pela Gestalt:

"Isso não impede que, precisamente porque concebida desta maneira, a Gestalt represente um tipo de "estrutura", que agrada a certo número de estruturalistas, cujo ideal, implícito ou confesso, consiste em procurar estruturas que possam considerar como "puras", porque as desejam sem história e, a fortiori, sem gênese, sem funçõese sem relações com o sujeito." (PIAGET, 1974, p.47)

Neste sentido, a conseqüência direta de se levar em conta a dimensão da temporalidade é a inclusão do sujeito na estrutura. Para Piaget, o modelo de campo de forças eletromagnéticas não deve ser generalizado para qualquer sistema, pois, segundo o autor, foi esse modelo que impediu o gestaltismo de pensar as questões relativas ao sujeito: 
"Ora, a preocupação com os efeitos de campo conduziu Köhler a não ver ato autêntico de inteligência senão na "compreensão imediata" (o insight), como se os tateios que precedem a intuição final não fossem já inteligentes. E, sobretudo, o modelo do campo é sem dúvida responsável pela pouca importância atribuída pelos gestaltistas às considerações funcionais e psicogenéticas e, por fim, às atividades do sujeito." (idem, ibidem)

Assim, a teoria piagetiana traz as atividades do sujeito para dentro da estrutura e busca entrelaçar a noção de estrutura com as transformações decorrentes da temporalidade. A estrutura, nesta concepção, é um sistema de transformação que comporta leis enquanto sistema, sem que estas conduzam para fora de suas fronteiras. Uma estrutura envolve os caracteres de total idade, de transformação e de auto-regulação. 0 sujeito, aqui, é o centro de funcionamento da estrutura. Diferentemente, na Gestalt o sujeito é apenas um palco onde se representam peças independentes dele e reguladas por antecipação por leis de equilibração física automática ( PIAGET, 1974).

A epistemologia genética centrou-se na psicogênese das estruturas mentais, com a finalidade de circunscrever os processos da aquisição do conhecimento. A pesquisa de Piaget visou a analisar as etapas e as estruturas que estão em jogo na construção (estamos aqui no campo do construtivismo) do sujeito cognoscente, a partir de uma visão empirista que compreende o sujeito humano como produto da interação do meio com o organismo.

0 interesse de Piaget centrou-se no estudo do sujeito do conhecimento, que deu origem à noção de sujeito epistêmico (SEM INÉRIO, 1996, p.32-33).

Essa perspectiva teórica do estruturalismo entende a aquisição do conhecimento como uma construção interna que conduz à transformação. 0 sujeito vai se transformando pelo processo de aprendizagem, e o que garante essa transformação é um permanente processo de equilibração. Este último rege o desenvolvimento humano a partir da busca do estado de equilíbrio por meio da irrupção do desequilíbrio e de permanentes reequilibrações. Assim, no processo de construção das estruturas cognitivas, trata-se de uma equilibração majorante, pela qual o equilíbrio envolve um salto de estrutura, a passagem para uma estrutura implicando a assimilação e a acomodação da estrutura anterior. A assimilação é a ação do sujeito sobre o meio, quando incorpora o meio. A acomodação é a modificação que o sujeito é obrigado a fazer em função da assimilação. Todo 0 processo se dá como um mecanismo de permanente transformação.

Nesse sentido, o construtivismo genético vai pesquisar a passagem de estruturas consecutivas, segundo um critério evolutivo que faz com que cada estrutura leve necessariamente, por equilibração, a uma estrutura subseqüente. Esses saltos de estrutura implicam uma evolução que se dá de forma similar à Aufhebung 
hegeliana, ${ }^{1}$ uma superação que ocorre pela suprassumição do objeto na constituição da consciência de si. A superação é, ao mesmo tempo, abolição e conservação do objeto. Assim, no estruturalismo piagetiano, a estrutura subseqüente assimila e acomoda a estrutura anterior, por meio de um mecanismo que faz com que a estrutura anterior continue existindo, sendo conservada na etapa seguinte do desenvolvimento humano. É inerente ao movimento permanente da equilibração majorante a idéia de evolução e progresso. Como aponta Passos (1992), a epistemologia genética afirma uma orientação do comportamento no sentido de uma finalidade, refletindo um percurso evolutivo do pensamento:

“Embora preocupado com o problema genético, a indagação acerca da formação das estruturas mentais não faz Piaget duvidar de um percurso evolutivo do pensamento. Há um sentido teleonômico da evolução intelectual, apesar do funcionamento da inteligência humana não estar submetido a um fim absoluto. 0 processo se faz sempre, mesmo que sem um termo definitivo para o qual a evolução se dirija." (p.137)

O sujeito epistêmico é o próprio sujeito cognoscente, o que revela como 0 sujeito piagetiano é correlato ao sujeito da ciência moderna. Com efeito, no estudo da gênese e evolução dos processos cognitivos, a lógica progressiva apa rece no nível do sujeito da mesma forma que está presente na história das idéias científicas:

"Piaget afirma a inter-rel ação entre a indagação psicogenética das estruturas mentais, isto é, o que se desenrola ontogeneticamente, e o curso progressivo do conhecimento científico ele mesmo. 0 construtivismo epistemológico se coloca, portanto, nesse limite entre o desenvolvimento individual das formas de conhecimento e o desenvolvimento histórico das idéias científicas." (PASSOS, 1992, p.137)

Dessa maneira, no caminho progressivo do desenvolvimento cognitivo da criança, Piaget define al guns estágios evolutivos. A criança, de início, encontra-se no estágio do pensamento prático sensório-motor, passa pelo estágio pré-operatório, desse vai para o pensamento concreto, para chegar finalmente ao pensamento lógico-formal, que atesta a capacidade de abstração hipotético-dedutiva da inteligência (PIAGET, 1964/ 1980). Ora, se a ciência moderna se caracteriza por descrever o universo por meio de fórmulas matemáticas (KOYRÉ, 1966/

\footnotetext{
${ }^{1}$ Passos ( 1992) mostra como na tese piagetiana o caráter progressivo, produtivo e cumulativo do tempo se apresenta como uma forma de hegelianismo. Segundo o autor, o sentido de finalidade presente em Piaget é problemático, pois entra em contradição com sua posição construtivista.
} 
1973), podemos apreender que cabe à criança piagetiana alcançar o estágio de um pequeno cientista:

“É assim que o psi cólogo situa um sujeito da ação - precursor do sujeito epistêmico - no contexto da inteligência sensório-motora. Definida como cronologicamente anterior e independente da linguagem, essa inteligência prática é compartil hada com os infra-humanos. Com a interiorização da ação em representação e, mais tarde, em operações lógico-intelectuais, o desenvolvimento culminaria em um sujeito definido finalmente pelas estruturas lógicas do pensamento hipotético-dedutivo. A esse nível formal, a atividade científica torna-se, então, franqueada ao sujeito epistêmico." (BASTOS, 1996, p.58)

Neste sentido, o sujeito epistêmico tem um caráter universal, apresentando uma dimensão temporal ascendente na direção do pensamento lógico, pois a gênese parte de uma estrutura mais simples para chegar a uma mais complexa:

“Portanto, não direi, simplesmente, que ela (a gênese) é a passagem de uma estrutura para outra, mas antes que a gênese é certa forma de transformação que parte de um estado A ealcança um estado B, sendo este mais estável que o primeiro." (PIAGET, 1964/ 1980, p.134)

Na tese piagetiana, assim, o tempo é evolutivo, e vai de uma estrutura a outra. Esse modo de pensar a gênese reafirma o que dissemos antes sobre a presença de um sentido final, uma teleonomia, nessa concepção do estruturalismo.

\section{A ESTRUTURA NA PSICANÁLISE}

A estrutura na psicanálise se insere no pensamento do estruturalismo francês, movimento que incluiu várias disciplinas e que floresceu especialmente na França ao final da Segunda Guerra M undial. Dentre seus expoentes, fizeram parte do movimento autores como Lévi-Strauss, LouisAlthusser, Roland Barthes, Jacques Derrida, Michel Foucault e, no caso da psicanálise, Jacques Lacan. Como aponta Dosse (1993), esses pensadores tomaram rumos bastante distintos em relação ao estruturalismo, sobretudo Derrida e Foucault, cujos trabalhos acabaram por desembocar em uma crítica antiestruturalista. ${ }^{2}$

Na psicanálise, foi Jacques Lacan, assim, quem introduziu a visão estruturalista na leitura que empreendeu do pensamento freudiano. Nos anos 1950, com

2 Ver, sobre isso, o livro de Dosse (1993), História do estruturalismo: 0 campo do signo. Campinas:

Editora da Unicamp. 
a introdução da lingüística de Saussure e a concepção de simbólico de LéviStrauss, Lacan traz o conceito de estrutura para o interior da teoria psicanalítica, definindo a psicanálise como "o campo da fala e da linguagem", regido pela lógica do significante. É neste cenário teórico que ele conceitua o inconsciente como transindividual.

Assim, em “Função e campo da palavra e da linguagem na psicanálise" (1953/ 1966), Lacan assevera o domínio da linguagem na constituição do conceito de inconsciente e das teorizações acerca da noção de interpretação, iniciando um longo percurso através do qual a psicanálise será direcionada pelos cânones do estruturalismo.

N este sentido, a psicanálise, principalmente a partir da interlocução que passa a ter com os pensamentos de Saussure e Lévi-Strauss, torna-se uma das correntes importantes do movimento estruturalista, pois seus conceitos são revistos e operacionalizados a partir do ponto de vista desse pensamento.

Sobre os critérios que definem o estrutural ismo, Deleuze (1967/ 1982) descreve al guns elementos que permitem analisar a presença da estrutura em certo domínio. Antes de tudo, é importante mostrar como a linguagem tem função prevalente neste pensamento, pois "só há estrutura daquilo que é linguagem" (p.272).

No texto "Em que se pode reconhecer o estruturalismo?" (1967/ 1982), Del euze propõe destacar al guns critérios formais de reconhecimento da estrutura na forma como é compreendida pelo movimento que ficou conhecido como o estruturalismo francês. Para isso, são analisados os seguintes elementos: 0 simbólico, a posição, o diferencial, a diferenciação, a série, a "casa" vazia e o sujeito.

No que diz respeito à questão que aqui nos interessa enfocar - a relação da estrutura com a temporalidade - deter-nos-emos nos quatro primeiros crité rios apresentados neste texto.

O primeiro critério, o simbólico, é um dos elementos de maior relevância na definição da estrutura. 0 simbólico se diferencia da dimensão do real e do imaginário, pois se articula diretamente com o registro da linguagem. Lacan apresenta a dimensão do simbólico em 1953 a partir de dois textos: a conferência sobre o "O simbólico, o imaginário e o real" e o texto "Função e campo da fala e da linguagem na psicanálise". Nesses textos, ele desenvolve a noção de Nomedo-Pai como o operador por excelência do simbólico e a compreensão de que 0 inconsciente é estruturado como uma linguagem.

O segundo critério, a posição, também chamado 'critério de local', mostra que 0 sentido que o elemento simbólico tem na estrutura é estritamente da ordem de uma vizinhança. 0 elemento tem aqui uma posição que obedece a uma dimensão topológica, pela qual os elementos desempenham seus papéis segundo uma ordem de vizinhança que é a da própria estrutura. 
0 diferencial, o terceiro critério, é o que faz com que os elementos se determinem reciprocamente em relações. A diferença entre os elementos é aquilo que os especifica, aquilo que faz com que sejam produzidos ao mesmo tempo os elementos e as relações diferenciais.

0 critério diferencial aponta para uma separação nítida entre a estrutura na psicologia e a estrutura na psicanálise. A partir deste critério foi que surgiu uma das críticas mais contundentes à noção de estrutura tal qual concebida pela psicologia - para Bertrand Russel, a concepção estrutural da forma em que é pensada na psicologia apresenta uma precariedade quanto à sua elucidação lógica. Segundo este autor, a origem matemática do estruturalismo deve ser buscada do lado do cálculo diferencial, elaborado por Russel como uma oposição ao cálculo infinitesimal. A teoria matemática de Bourbaki emprega o termo 'estrutura' em um sentido bem diferente do estruturalismo, pois operacional iza el ementos não especificados. 0 cálculo diferencial da forma que foi interpretado por Russel integra os elementos numa lógica das relações, pela qual os elementos vão se especificar por meio de uma determinação recíproca.

É nesse sentido que, de maneira diferente da psicologia, a estrutura na psicanálise não pode ser aplicada à idéia de conjuntos, em que o todo determina as partes, como na Gestalt - a noção de estrutura se aplica às relações entre os elementos, que são as relações diferenciais. Na psicologia, a estrutura consiste, como vimos, em todos holísticos que determinam tanto o tipo dos elementos como as relações que se estabelecem entre eles. Não tem importância, nesta perspectiva, a relação entre os elementos. Na psicanálise, a estrutura é um sistema que define as relações entre os elementos. São estas relações que, justamente, determinam a estrutura. Trata-se de um sentido inverso ao da psicologia, pois os elementos é que são determinantes para o todo, e não o todo que determina os elementos. Os elementos, na estrutura psicanalítica, não existem independentemente das relações diferenciais, pois são estas que fazem com que aqueles sejam produzidos.

0 quarto critério é a diferenciação. Este aspecto é particularmente importante no que tange à variável 'tempo', pois na estrutura as relações diferenciais se atualizam na medida que se encarnam em uma forma determinada. 0 tempo da estrutura se instaura à proporção que se atualiza. Nesta atualização da estrutura ocorre uma diferenciação - atualizar-se, para ela, é, precisamente, diferenciar-se:

"E é justamente porque a estrutura não se atual iza sem se diferenciar no espaço e no tempo, sem diferenciar, assim, espécies e partes que a efetuam, que devemos dizer, neste sentido, que a estrutura produz essas espécies e essas partes. Ela as produz como espécies e partes diferenciadas (...)" (DELEUZE, 1967/ 1982, p.285) 
Assim, o tempo da estrutura vai do virtual ao atual. 0 que designa o modo da estrutura é a virtualidade. Há uma virtualidade indiferenciada e quando a estrutura se encarna ela se diferencia e produz as suas partes já como partes diferenciadas. Se na estrutura psicológica o todo determina as partes, na estrutura psicanalítica as relações que se estabelecem entre as partes vão determinar tanto as partes como o todo.

Neste sentido, podemos dizer que o tempo vai da estrutura às suas atualizações, e não de uma estrutura à outra, como vimos na gênese do empirismo piagetiano.

Pensar um tempo que se atualiza distingue sobremaneira a estrutura psicanalítica da estrutura psicológica, pois, como vimos, se na Gestalt o tempo nem fazia parte da estrutura, em Piaget o tempo é introduzido na estrutura, mas a partir de uma concepção evolutiva do tempo.

Del euze (1967/ 1982), neste texto, mostra como a questão da temporalidade é fundamental para se definir o modo da estrutura do ponto de vista do estruturalismo francês:

"Portanto, a posição do estruturalismo relativamente ao tempo é bastante clara: 0 tempo é sempre um tempo de atualização, segundo o qual se efetuam, em ritmos diversos, os elementos de coexistência virtual. 0 tempo vai do virtual ao atual, isto é, da estrutura às suas atualizações, enão de uma forma atual à outra forma." (DELEUZE, 1967/ 1982, p.285)

Dessa maneira, vemos como o el emento simbólico inerente à estrutura psicanalítica faz com que esta seja produzida pelas relações diferenciais, que terão sempre um tempo que é o da atualização: "o inconsciente da estrutura é um inconsciente diferencial" (idem, p.287). 0 pensamento simbólico revela, assim, os mecanismos diferenciais, mecanismos esses que ficam ocultos na teoria psicológica da estrutura. A fórmula da estrutura na Gestalt que faz com que o todo determine as partes não leva em conta o elemento simbólico, ficando no nível do imaginário, como explica Deleuze:

“Mas é justamente aqui que passa a fronteira entre o imaginário e o simbólico: 0 imaginário tende a refletir e a reagrupar sobre cada termo 0 efeito total de um mecanismo de conjunto, ao passo que a estrutura simbólica assegura a diferenciação ('différentiation') dos termos e a diferenciação ('différenciation') dos efei tos. Donde a hostilidade do estruturalismo em relação aos métodos do imaginário." (idem, p.286)

Quando Lacan acompanha Lévi-Strauss, é este elemento simbólico da estrutura que ele persegue. Em "A ciência e a verdade" (1966), Lacan mostra como 0 
estruturalismo introduz o sujeito nas chamadas "ciências humanas" ( p.861), termo posto por ele entre aspas por não acreditar que tais ciências pudessem existir. Quanto a Piaget, Lacan mostra que ele tem o mérito de não ficar na ciência do homem, de trazer o sujeito para a sua teoria, mas, no entanto, seu sujeito epistêmico seria muito mai s da ordem do ego, do imaginário, e não traria o elemento simbólico tão caro ao estruturalismo na psicanálise. Como observa Bastos (1996), enquanto Lacan institui a precedência da ordem simbólica sobre o sujeito do significante, Piaget elabora a gênese empírica do sujeito epistêmico. 0 sujeito cognoscente não é o sujeito do significante, mas a extensão de "uma suposta organização biológica prévia não submetida à ordem simbólica” (p.58).

\section{ESTRUTURA E TEMPORALIDADE}

É justamente por este aspecto da diferenciação que podemos analisar a variável tempo na estrutura. Por ser um tempo que se diferencia, podemos observar que se trata do tempo da irreversibilidade, e não da reversibilidade.

Se o tempo da irreversibilidade é aquele que diferencia um antes e um depois, o tempo da reversibilidade faz uma simetria entre o que veio e o que virá.

Como mostram Prigogine e Stengers em A nova aliança (1984) , a ciência clássica definiu uma concepção de mundo mecanicista que se queria estável. A ordem só teria como surgir a partir de noções como causalidade, determinismo, racionalidade. Para que só haja organização no equilíbrio, faz-se necessário pensar o tempo como reversível, isto é, não tendo uma direção determinada. 0 tempo da reversi bilidade estabelece que o tempo seja uma série contínua, homogênea e infinita. A dinâmica newtoniana aceita que o tempo marche indiscriminadamente para o passado ou para o futuro, não fazendo discriminação entre passado, presente e futuro. Assim, no mundo mecânico é possível que, quando aplicada às mesmas condições de força, velocidade etc., haja um retorno ao mesmo estado em que se estava antes, na medida que não há diferenciação entre 0 antes e 0 depois. $\mathrm{Na}$ dinâmica newtoniana, a relação entre a causa e seu efeito é formulada como reversível: não há nenhuma perda, nenhuma diferença se interpõe entre uma e outro. A reversibilidade apregoa uma dimensão abstrata do tempo, na qual as categorias de racionalidade, causalidade e determinismo funcionam perfeitamente.

$\mathrm{Na}$ irreversibilidade do tempo, por sua vez, o tempo flui em uma direção determinada: rumo ao futuro, não sendo concebível uma volta ao passado. 0 tempo irreversível diferencia o passado do presente e do futuro, discriminando 0 antes e o depois. Nesta perspectiva, é possível pensar que há ordem fora da estabilidade. A noção de equilíbrio não é aqui tão fundamental, pois é possível conceber uma forma de organização no desequilíbrio.

Assim, a termodinâmica - a primeira ciência não clássica - descobriu os processos de organização espontânea e as estruturas dissi pativas que levam a que 
haja junção entre acaso e necessidade. Com isso, introduziu na física a "flecha do tempo":

"Das duas herdeiras da ciência do calor, a ciência das conversões de energia e a ciência das máquinas térmicas - ambas concebidas ainda segundo o modelo clássico - nasceu a primeira ciência não clássica, a termodinâmica. Foi ela, diz-se isso inúmeras vezes, que introduziu a'flecha do tempo' na física." (PRIGOGINE \& STENGERS, 1984, p.10)

É desse modo que podemos dizer que a noção de irreversibilidade conduz à elaboração de conceitos como estrutura e história. A irreversibilidade obriga que se pense a estrutura atrelada à história: "No futuro, a física retoma o que a ciência clássica negava em nome da reversibilidade dos comportamentos elementares: as noções de estrutura, de função e de história" (idem, ibidem). Foi destruído, com a irreversibilidade, o demônio determinista de Laplace que, por ter a onisciência do passado, do presente e do futuro, podia estabelecer uma previsão absoluta do futuro.

Na psicanálise, o tempo é o da irreversibilidade. 0 tempo que Freud definiu como sendo o do inconsciente é o Nachträglichkét, o a posteriori. Como sinaliza Gondar (1995), o modo freudiano de pensar o tempo não aponta para uma noção abstrata do tempo, pois seu funcionamento é intrínseco ao sujeito e às operações que levam à sua produção. É neste sentido que se pode dizer que 0 tempo do inconsciente é real e não abstrato, já que o sujeito é capaz de criar um tempo que Ihe seja próprio. Quando Freud afirma que o inconsciente é atemporal, é justamente a concepção abstrata do tempo que ele refuta, pois

"se o inconsciente implica um tempo, este não deve ser entendido como grandeza e quantificabilidade preexistentes por si mesmas, e tampouco um tempo neutro onde se poderia dar indiferentemente este ou aquele evento." (GONDAR, 1995, p.65)

Assim, há no tempo psicanalítico do a posteriori uma dissimetria entre 0 antes e o depois. Se num tempo reversível essa discriminação não é realizada, a irreversibilidade reconhece um marco diferencial entre 0 antes e 0 depois, concebendo-os como desiguais. Como observa a autora, esse marco se encontra, para o inconsciente, na produção de sentido:

"A cada instante que os traços mnêmicos se rearranjam, produz-se um novo sentido, e esse sentido é irreversível - não porque não possa ser produzido um outro que 0 modifique, mas porque não há possibilidade de retorno ao instante anterior. Esse sentido só pode ser destituído ou ultrapassado pela criação de um outro, que também se apresentará como diferente com relação aos que o precederam: qualquer 
produção nova é por si só suficiente para impedir a simetria entre um antes e um depois." (GONDAR, 1995, p.66)

Em Piaget, observamos que a gênese empírica funciona a partir do tempo da reversibilidade. A psicogênese das estruturas mentais da criança é o correlato, como dissemos antes, do próprio caminho evolutivo da ciência. $\mathrm{Na}$ " equilibração majorante" está presente, assim como na ciência, a noção de progresso. A criança, pela aquisição de suas estruturas cognitivas, caminhará nos seus estágios evolutivos até chegar ao pensamento lógico formal. Neste último, tal qual na ciência clássica, o tempo é abstrato e reversível. A criança cientista poderá, com a aquisição do pensamento hipotético-dedutivo, no qual não é mais necessária a referência à experiência concreta, abstrair e formular conceitos reversíveis.

A reversibilidade é justamente a capacidade de abstração do pensamento lógico-formal, que possi bilita entender que se dois mais quatro é igual a seis, quatro mais dois também é igual a seis. Trata-se de um pensamento proposicional, pelo qual a criança não precisa se ater ao real, mas pode fazer proposições sobre algo que seja possível. 0 conceito de reversibilidade, em Piaget, permite que a criança estabel eça a conservação da substância, do volume e do peso dos objetos, o que, de novo, só será possível de ser feito a partir da capacidade de abstração do pensamento:

“Como, então, se elaboram estas noções de conservação? (...) Resultam de um jogo de operações, coordenadas entre si em sistemas de conjuntos, e cuja propriedade mais notável, em oposição ao pensamento intuitivo da primeira infância, é a de serem reversíveis." (PIAGET, 1964/ 1980, p.49)

Dessa maneira, o tempo da estrutura psicológica funciona segundo os moldes da ciência clássica. A necessidade de se pensar o desenvolvimento psicogenético pela via do equilíbrio e da estabilidade que se supõe para o campo psicológico conduz a uma noção de estrutura na qual o tempo é o da reversibilidade. Por outro lado, a correlação quase imediata do sujeito epistêmico com a ciência levou a psicogênese a seguir o paradigma da dinâmica newtoniana, que compreende o tempo como abstrato, reversível e evolutivo.

Neste sentido, podemos diferenciar nitidamente a temporalidade na estrutura psicológica e na estrutura psicanalítica. Em uma, o tempo é reversível e admite a noção de progresso e evolução, já que a estrutura subseqüente não conduz a uma perda, mas a um processo majorante de superação que conserva a estrutura anterior. Em outra, o tempo é irreversível, marcando uma diferenciação entre 0 antes e 0 depois, afirmando como indissociável a necessidade e 0 acaso, permitindo, portanto, que o inconsciente tenha um tempo que lhe seja próprio. 
Portanto, a produção subjetiva na psicanálise possui um modo de temporalização que implica uma experiência de perda e de dissi pação. Por meio desta última, o sujeito pode ir criando a cada vez um novo sentido para sua existência, diferenciando sempre o presente do passado, e podendo, com seu desejo, apostar na dimensão do futuro.

Recebido em 22/ 5/ 2006. Aprovado em 22/ 7/ 2006.

\section{REFERÊNCIAS}

BASTOS, A. (1996) "Piaget em ciência e verdade", in FREIRE, A. B. et alli (org.) . A ciência e a verdade um comentário. Rio de Janei ro: Revinter.

DELEUZE, G. (1967/ 1982) “Em que se pode reconhecer o estruturalismo?", in CHÂTELET, F. (org.). História da filosofia: 0 século XX. Rio de Janeiro: Zahar.

DOSSE, F. ( 1993) História do ettruturalismo: 0 campo do signo. Campinas: Editora da Unicamp.

GONDAR, J. (1995) “Estrutura e tempo: reversibilidade versus irreversibilidade", in Os tempos de Freud. Rio de Janeiro: Revinter.

KOFFKA, K. (1975) Princípios de Psicologia da Gestalt. São Paulo: Cultrix.

KOYRÉ, A. ( 1966/ 1973) Études d'hi stoiredela penséescientifique. Paris: Gallimard.

LACAN, J. (1953/2005) "Le symbolique, l'imaginaire et le réel", in MILLER, J. A. \& MILLER, J. (org.). Des noms du-père. Paris: Champ Freudien/ Seuil.

. (1953/ 1966) "Fonction et champ de la parole et du langage en psychanalyse", in Écrits. Paris: Seuil.

. (1966/ 1966) "La science et la vérité", in Écrits. Paris: Seuil.

LEW IN, K. (1970) Problemas de dinâmica de grupo. São Paulo: Cultrix.

PASSOS, E. (1992) "O sujeito cognoscente entre o tempo e o espaço". Tese de Doutorado, UFRJ.

PIAGET, J. ( 1964/ 1980) "Gênese e estrutura na psicologia da inteligência", in Sés estudos de psicologia. Rio de Janei ro: Forense.

. (1974) 0 estruturalismo. São Paulo: Difel.

PRIGOGINE, I. \& STEN GERS, I. (1984) A nova aliança. Brasília: Editora Universidade de Brasília.

SEMIN ÉRIO, F. L. P. (1996) Piaget: o construtivismo na Psicologia ena Educação. Rio de Janeiro: Imago.

WERTHEIMER, M. (1968) Productive Thinking. Londres: Associated Book Publisher.

Isabel Fortes

isafortes@bol.com.br 